\title{
Scaling the hydraulic functions of a water repellent sandy soil
}

\author{
Heiner Stoffregen and Gerd Wessolek* \\ Institute of Ecology, Soil Protection Group, Technical University, Ernst Reuter Platz 1, 10587 Berlin, Germany
}

Received March 19, 2014; accepted April 22, 2014

\begin{abstract}
A b s t r a c t. The heterogeneity of both unsaturated hydraulic conductivity and water retention was measured with a high spatial resolution on a transect using an evaporation method. Fifteen undisturbed $100 \mathrm{~cm}^{3}$ soil cores were taken on a transect every 10 $\mathrm{cm}$ from the topsoil of a water repellent sandy site. Five dynamic water retention curves and four unsaturated conductivity curves were determined for each core. We conducted measurements without further saturation in the laboratory in order to achieve field-like conditions. The initial water contents were heterogeneous, indicating different hysteretic conditions and water repellent areas. The scattering of the water retention curves was high, while the heterogeneity of unsaturated conductivity curves was unexpectedly low. Two scaling approaches were used to describe the heterogeneity: one with and one without considering hysteresis. The concept of scaling applies well to describing the heterogeneity of both hydraulic functions. Including hysteresis leads to similar results than excluding hysteresis. The distribution of the hydraulic conductivity and the water retention were independent from each other. The results give important information for numerical simulation of the water flow with heterogeneous hydraulic functions.

K e y w o r d s: scaling, hydraulic conductivity, water retention, hysteresis, water repellency
\end{abstract}

\section{INTRODUCTION}

Spatial heterogeneity is one of the main problems for an accurate determination of the water and solute movements in soils. Among others, effects of aggregate size and hysteresis on water movement have been studied intensively in the past (Carminati et al., 2008; Sławiński et al., 2011; Lipiec et al., 2007; Witkowska-Walczak, 2006). From these experiments, one can conclude that:

- heterogeneity increases the experimental effort considerably and leads,

- to more complicate numerical models. Most model concepts are based on the Richards equations, using mathematical functions for the soil hydraulic properties.

*Corresponding author e-mail: gerd.wessolek@tu-berlin.de
However, one problem is the description of heterogeneous functions. The idea of scaling contains a unique function for the hydraulic property of a horizon and the description of the spatial heterogeneity in this layer by a scalar which is the scaling factor. Miller and Miller (1956) developed a theory of coupling scaling factors of unsaturated hydraulic conductivity and water retention. The theory is based on the dependence of the matric potential and unsaturated hydraulic conductivity on the pore size. This could lead to a considerable reduction of the experimental effort, as measuring the unsaturated hydraulic conductivity is much more time consuming than measuring the retention curve.

The approach of scaling is commonly applied in the field of hydrology, but it has also been applied to the hydraulic functions in soil science. Sposito (1998) gives an overview of scaling in hydrology and soil science. Most investigations on the hydraulic functions were made using water retention data (Deurer et al., 2000; Kosugi and Hopmans, 1998; Millan and Gonzalez-Posada, 2005), much fewer were carried out using the unsaturated hydraulic conductivity. Clausnitzer et al. (1992) introduced an algorithm to scale simultaneously conductivity and water retention. Using two sets of data, they proved the feasibility of this concept. Rockhold et al. (1996) applied it successfully for simulation of the water flow and tritium transport. Tuli et al. (2001) applied a physically based scaling approach of Kosugi and Hopmans (1998) on 143 soil samples. They were able to show that the theoretical interpretation of a log normal distribution of scaling factors was applicable to the simultaneous scaling of hydraulic functions. Other authors came to independent scaling functions for unsaturated conductivity and water retention. Hendrayanto et al. (2001) measured unsaturated conductivity and water retention for six soil profiles in a forestry soil and scaled the measurements for 
the entire profile. The variances in the scaling factors were high compared to studies of agricultural soils. They found huge errors when estimating the unsaturated hydraulic conductivity using the scaling factors of water retention measurements or vice versa. When using a combined scaling approach, the estimation led to slightly better results. Mallants et al. (1996) determined the spatial heterogeneity of water retention and saturated hydraulic conductivity. They found much higher heterogeneity of saturated conductivity. Warrick et al. (1977) and Russo and Bressler (1980) did not find relation between the scaling of unsaturated hydraulic conductivity and water retention. Kodesova et al. (2003) presented scaling approach of two-phase capillary pressuresaturation relationships for both water-air and oil-air system. They found that the scaling factors for both systems consist of the ratios of the interfacial tensions and the wetting angles of both liquids. Zhu and Mohanty (2006) investigated the effective hydraulic parameters for transient infiltration under ponding conditions for heterogeneous soils in terms of finding the optimal averaging schemes for hydraulic and environmental parameter fields. They found that the variability of the Miller-Miller scaling factors has a much stronger effect on the ensemble flux behaviour than saturated water content and ponding depth.

However, only a few studies investigated scaling factors with a high spatial resolution. Deurer et al. (2000) measured the water retention of three vertical grids $(2 \mathrm{~m}$ wide and $1.4 \mathrm{~m}$ deep) and used linear and nonlinear scaling to analyse the data. They found a very short correlation length below $0.2 \mathrm{~m}$. The effect of water repellency on scaling factors has not been investigated until now.

Hysteresis is another important factor for the heterogeneity of the hydraulic status in the field. The dependence on the water content, matric potential, and hydraulic conductivity is strongly influenced by hysteresis (Basile et al., 2003; Naasz et al., 2005). The formulation of Mualem (1984) forms the basis for most models of hysteresis. Kool and Parker (1987) and Luckner et al. (1989) developed an empirically closed-form expression for hysteretic soil hydraulic properties by scaling the water content for actual hysteretic loops of the water retention curve. Most models of hysteresis assume that the unsaturated hydraulic conductivity is a unique function of the water content. The hysteretic behaviour of conductivity as a function of the matric potential will depend on the hysteresis of the water retention curve.

The main objective of this study is to characterize the heterogeneity of unsaturated hydraulic conductivity and water retention with a high spatial resolution and to analyse a connection between both heterogeneities. The design of the laboratory experiment was related closely to the field condition. The terminology 'scaling' is used in this article for the scaling of the matric potential, not of the water content.

The theory of Miller and Miller (1956) is based on the concept of capillary attraction for the matric potential and on the Hagen-Poiseuille equation for conductivity. In these concepts, the matric potential and the hydraulic conductivity are functions of the pore radius. The matric potential $h$ of a tube with the radius $r$ is:

$$
h=-\frac{2 \sigma \cos \varphi}{\rho_{l} g r},
$$

where: $h$ is matric potential, $r$ is pore-radius, $\sigma$ is surface tension of water, $\rho_{l}$ is density of liquid water, $g$ is gravitational acceleration, and $\varphi$ as contact angle.

The Hagen-Poiseuille equation determines the hydraulic conductivity $K_{\text {tube }}$ for a single tube as:

$$
K_{\text {tube }}=\frac{\pi r^{4}}{8 \mu}
$$

where: $\mu$ is the viscosity of water. The amount of water in a tube is proportional to $r^{2}$. For two bundles of tubes with the same water content but different radii $R$ respectively $r$, the ratio of hydraulic conductivities becomes:

$$
\frac{K_{R}}{K_{r}}=\frac{R^{2}}{r^{2}} .
$$

If the radius is scaled by a factor $\delta_{S}$ and the matric potential is scaled by a factor $\delta_{S}$ (ie $h \rightarrow \delta_{S} h$ ), the unsaturated hydraulic conductivity will change with $\delta_{S}^{2}$.

Mualem (1976) used Eqs (1) and (3) for his functional link between the water retention and the relative unsaturated hydraulic conductivity. He introduced the additional dependence $\theta^{l}$, where the parameter $l$ is often set to 0.5 . This leads to a non-quadratic relation of the scaling of water retention and unsaturated conductivity.

The soil hydraulic properties were described by the analytical function of van Genuchten (1980) and the model of Mualem (1976):

$$
\begin{gathered}
\theta(h)=\left\{\begin{array}{cc}
\frac{\theta_{S}-\theta_{R}}{\left[1+(\alpha|h|)^{n}\right]^{m}}+\theta_{R} & h<0, \\
\theta_{S} & h \geq 0
\end{array}\right. \\
K_{u}(h)=K_{S A T} \frac{\left\{1-(\alpha|h|)^{n-1}\left[1+(\alpha|h|)^{n}\right]^{-m}\right\}^{2}}{\left[1+(\alpha|h|)^{n}\right]^{m l}} \\
\text { with } m=1-1 / n,
\end{gathered}
$$

where: $\theta(h)$ is water retention; $\theta_{S}$ and $\theta_{R}$ are the saturated and residual water contents; $\alpha, n, m(=1-1 / n), l$ are empirical coefficients; and $K_{u}(h)$ is unsaturated conductivity; $K_{S A T}$ is the saturated hydraulic conductivity.

The principle of scaling of the hydraulic functions is to use one set of van Genuchten parameters for each single soil horizon. The scaling factors $\delta_{S}(x, z)$ describe the heterogeneity 
of the hydraulic functions. The heterogeneous functions are then reduced to a heterogeneous scalar $\delta_{S}(x, z)$. The concept leads to scaled functions of water retention $\theta^{\text {scal }}(h)$ and unsaturated hydraulic conductivity $K_{u}{ }^{s c a l}(h)$ :

$$
\begin{aligned}
& h \Rightarrow \delta_{S}^{i} h \text { with } \sum_{i=1}^{N_{\theta}} \frac{1}{N_{\theta}} \delta_{S}^{i}=1, \\
& \theta^{\text {scal }}(h)=\left\{\begin{array}{cc}
\frac{\theta_{S}-\theta_{R}}{\left[1+\left(\delta_{S} \alpha|h|^{n}\right)\right]^{m}}+\theta_{R} & h<0 \\
\theta_{S} & h \geq 0,
\end{array}\right. \\
& K_{u}^{s c a l}(h)=K_{S A T} \frac{\left\{1-(\alpha|h|)^{n-1}\left[1+(\alpha|h|)^{n}\right]^{-m}\right\}^{2}}{\left[1+\left(\delta_{S} \alpha|h|\right)^{n}\right]^{m l}} .
\end{aligned}
$$

In a logarithmic scale, the scaling procedure results in a parallel shift along the axis of $\log h$.

The parameters for the hydraulic function $K(h)$ and $\theta(h)$ were calculated during the optimization of the scaling process. At the beginning of the optimization, all scaling factors were set to 1 . The deviation between the calculated value and the measured value were determined by:

$$
\begin{gathered}
S S Q_{\theta}\left(\theta_{S}, \theta_{R}, \alpha, n, \delta_{S}^{1}, \ldots, \delta_{S}^{N_{k}}\right)=\sum_{i=1}^{N_{\theta}} \sum_{j=1}^{n_{i}}\left[\theta_{j}^{\text {meas }}(h)-\right. \\
\left.\theta^{\text {scal }}\left(h_{j}, \theta_{S}, \theta_{R}, \alpha, n, \delta_{S}^{i}\right)\right]^{2}
\end{gathered}
$$$$
S S Q_{k}\left(\alpha, n, K_{S A T}, \delta_{S}^{1}, \ldots, \delta_{S}^{n_{\theta}}\right)=\sum_{i=1}^{M_{K}} \sum_{j=1}^{m_{i}}\left[\log \left(K_{j}^{\text {meas }}(h)\right)\right.
$$$$
\left.-\log \left(K_{u}^{s c a l}\left(h, \alpha, n, K_{S A T}, \delta_{S}^{i}\right)\right)\right]^{2}
$$

$N_{\theta}$ and $M_{K}$ are the number of positions where the water retention resp. hydraulic conductivity was measured, $n_{i}$ and $m_{i}$ are the number of measurements at a position $i$ (at different matric potentials). An average deviation $\overline{\Delta \theta}$ and $\overline{\Delta \log (K)}$ between the data and the hydraulic function is the root of the $S S Q$ divided by the number of data:

$$
\overline{\Delta \theta}=\sqrt{\frac{S S Q_{\theta}}{N_{\theta}}}, \overline{\Delta \log (K)}=\sqrt{\frac{S S Q_{K}}{M_{K}}} .
$$

The functions $\mathrm{SSQ}_{\theta}$ and $S S Q_{K}$ were minimized separately using a numerical solver, leading to optimized scaling factors for each position and optimized van Genuchten parameters for the entire horizon. The high number of optimized parameters is not a problem, because there is no functional dependence between the scaling factors of different positions.

The experiments described in this paper are evaporation experiments and, therefore, always drying branches. However, since the hydraulic conditions were measured without further saturation, hysteresis might be taken into account to describe the different initial conditions of the soil core. Approaches like that of Kool and Parker (1987) use the scaling of the water content to describe the actual drying curve $\theta^{a, d}(h)$. By scaling the water content of the main drying curve $\theta^{d}(h), \theta^{a, d}(h)$ goes from the reversal point (in our case the initial conditions with matric potential $h_{\Delta}$ and water content $\theta_{\Delta}$ ) to the residual water content $\theta_{R}$ for $h \rightarrow-\infty$. Using these conditions, the actual drying curves can be calculated as follows:

$$
\theta^{a d}(h)=\delta_{\theta}^{d}\left(\theta^{d}-\theta_{R}\right)+\theta_{R},
$$

$\delta_{\theta}$ is the scaling parameter of the water content. The condition $\theta^{a d}\left(h_{\Delta}(x, z)\right)=\theta_{\Delta}(x, t)$ leads to the determination of $\delta_{\theta}^{i}\left(x_{i}, z_{i}\right)$. The water retention can then be described by a van Genuchten function with a new parameter $\theta_{S}^{a}\left(x_{i}, z_{i}\right)$ :

$$
\begin{gathered}
\theta^{a}(h)=\frac{\theta_{S}^{a}-\theta_{R}}{\left[1+(\alpha|h|)^{n}\right]^{m}}+\theta_{R} h<h_{\Delta} \\
\theta_{S}^{a}=\delta_{\theta}^{d}\left(\theta_{S}-\theta_{R}\right)+\theta_{R} .
\end{gathered}
$$

The actual drying curves must be calculated separately for each position. This hysteretic model of Kool and Parker (1987) does not require knowledge of the wetting or drying history, so that the initial values $h_{\Delta}$ and $\theta_{\Delta}$ do not have to be part of the main drying curve. Figure 1 shows the main drying curve, two actual drying curves with different initial water contents and matric potentials, and the effect of scaling of the water retention curve. In the diagram, the scaling of the water content results in a stretching along the axis of the water content.

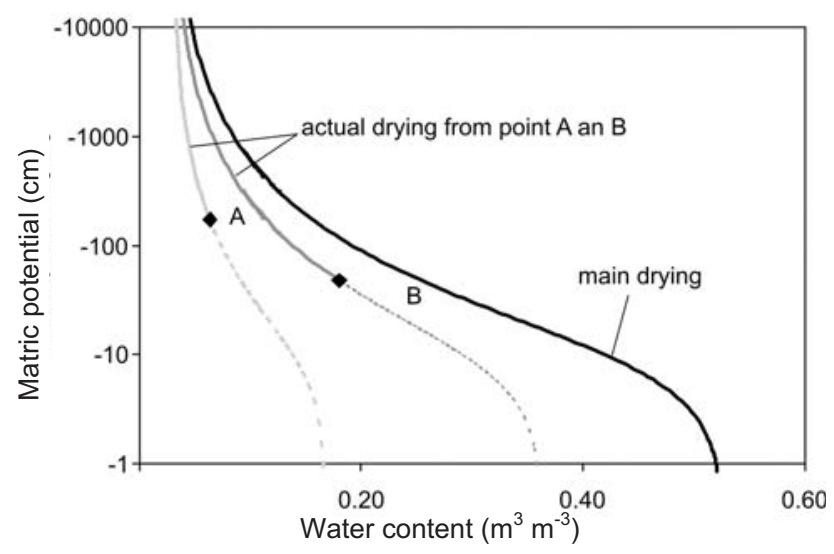

Fig. 1. Main drying (black) and actual drying curves starting from point A (light grey) and B (dark grey). 


\section{MATERIAL AND METHODS}

We collected the soil cores from a former wastewater application site located at the northern city limit of Berlin

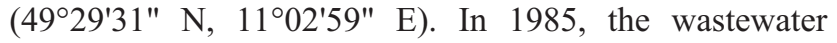
application was stopped after nearly one hundred years of operation. The ground was levelled and an effort was made to afforest the region. The attempt failed and most trees died, mainly due to water shortage during the summer time (Schlenther et al., 1996). Today, dry grassland (mainly couch grass: Elytrigia repens) is found at the site. The soil is a hortic anthrosol with $20-80 \mathrm{~cm}$ of organic topsoil upon medium sized sand. The organic matter content of the topsoil horizon ranges mainly between 4 and $6 \%$, seldom up to $30 \%$. Below the topsoil, it is approximately $1 \%$, in the sand of the $\mathrm{C}$ horizon below $0.5 \%$. The non-calcareous fluvial sand contains less than $0.8 \%$ clay, whereas the topsoil and organic sediments can contain up to $6 \%$. The topsoil becomes water repellent when it dries out to levels below the critical water content. Below a water content of $0.10 \mathrm{~g} \mathrm{~g}^{-1}$ $\left(0.12 \mathrm{~m}^{3} \mathrm{~m}^{-3}\right.$, the critical water content of water repellency), the soil becomes water repellent (Täumer et al., 2005).

Sixteen undisturbed cores were taken from the field moist soil at a depth of $30-40 \mathrm{~cm}$. Based on an experimental set-up described by Plagge (1991), standard soil core samplers with a length of $10 \mathrm{~cm}$ and a diameter of $5.5 \mathrm{~cm}$ $\left(237 \mathrm{~cm}^{3}\right)$ or $8.4 \mathrm{~cm}\left(550 \mathrm{~cm}^{3}\right)$ were used. Five pairs of holes were equally spaced along the core sampler for installing a mini-tensiometer and TDR-probes (Easy Test Ldt. Lublin, Poland). The vertical distance between the holes was $2 \mathrm{~cm}$, with the highest and lowest hole located at a distance of $1 \mathrm{~cm}$ from the ends of the core sampler. The matric potential and water contents were measured at the depths of $1,3,5,7$, and $9 \mathrm{~cm}$. The measurement volume of the TDR probe is approximately a cylinder of $5 \mathrm{~cm}$ respectively $8 \mathrm{~cm}$ length and $6 \mathrm{~mm}$ diameter vertical $2 \mathrm{~cm}$. Water fluxes were calculated from changes in the water content. It was not possible to weigh the soil cores during the experiments to calculate the total evaporation or infiltration fluxes because of the cable connections between the sensors and measuring devices. All measurements were carried out automatically, usually once every hour. The experimental set-up is shown in Fig. 2. The accuracy for the measurement of water content changes is within the range of $0.002 \mathrm{~m}^{3} \mathrm{~m}^{-3}$. The temperature in the laboratory was about $20^{\circ} \mathrm{C}$. Stoffregen (1998) gives a detailed description of the experimental setup and error analysis.

Since it was not possible to measure all cores immediately, they were divided into two series. Half of the cores were sealed and put into a refrigerator; the other half was measured immediately. The weight of the stored cores was controlled afterwards in order to ensure that they did not lose water. The initial status of both cores at the beginning of the experiments corresponded to the saturation status in the field. The top ends of the cores were opened to allow evapo-
Evaporation

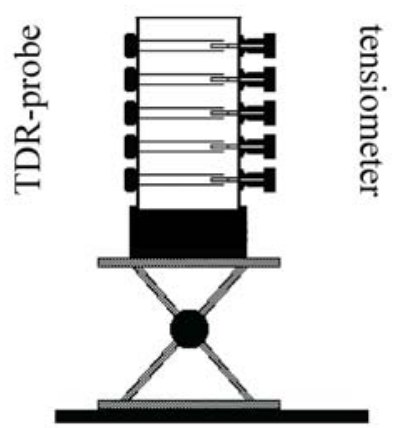

Fig. 2. Experimental setup of the evaporation experiment (Plagge, 1991).

ration, while the bottom ends remained sealed. The evaporation was stopped after several days when the top compartment had dried out. Finally, the cores were sliced and used to measure the gravimetrical water contents and the water drop penetration times (WDPT) (de Letey et al., 2000). The soil bulk density was determined for each core. TDR measurements were analyzed using the calibration function of Roth et al. (1992). To achieve a higher precision of the measurement of the total water content, the TDR results were corrected using the difference between TDR results and gravimetrically measured water content at the end of the experiments. A stone was found inside the core taken at $90 \mathrm{~cm}$, which made it impossible to install the tensiometer and TDR probes. This core was left out of the further calculations.

Unsaturated hydraulic conductivities were calculated combining Darcy Eq. (14) with a continuity Eq. (15). Gradients of the matric potential $\partial_{z} h(z, t)$ were calculated from a splineinterpolation of tensiometer readings at each time step. The water fluxes $q(z, t)$ at different depths $z$ and times $t$ were determined from temporal changes of the water content $\partial_{t} \theta(z, t)$. Equation (15) assumes that the TDR measurements are representative for an entire $2 \mathrm{~cm}$ compartment $i$, and that there is a zero flux at the bottom. Unsaturated hydraulic conductivities $K_{u}(\mathrm{~h})$ as a function of the matric potential $h$ were calculated at the depths of $2,4,6$, and $8 \mathrm{~cm}$ from the top of the core:

$$
\begin{gathered}
q(z, t)=-K_{u}(h, z)\left(\partial_{z} h(z, t)+1\right), \\
q\left(z_{i}, t\right)=\sum_{j=1}^{i} \partial_{t} \theta\left(z_{j}, t\right) \Delta z_{j} .
\end{gathered}
$$

The differentiation in time in Eq. (15) leads to a very high sensitivity for scattering of the water content measurements. The scattering of water content changes is due to the small changes in the water contents between two measurements (for a temporal resolution of $1 \mathrm{~h}$ ). These changes are smaller than the accuracy reached by measuring water content changes (about $0.002 \mathrm{~m}^{3} \mathrm{~m}^{-3}$ ). The calculation of the unsaturated hydraulic conductivity is limited by the accuracy of the tensiometers. Therefore, a threshold for the 
hydraulic gradient of $0.5 \mathrm{~cm} \mathrm{~cm}^{-1}$ was used. For lower values, the conductivities were not calculated. The calculations were carried out using the program KUPFER (Stoffregen, 1998).

The program SURFER was employed to calculate the semivariograms of the data. The measurement grid was 150 $\mathrm{x} 10 \mathrm{~cm}$ or $150 \times 8 \mathrm{~cm}$, with a nodal distance of $10 \mathrm{~cm}$ in the horizontal direction and $2 \mathrm{~cm}$ in the vertical direction. Twodimensional variograms were calculated in the horizontal direction. Due to the small number of vertical positions, the vertical semivariograms were not calculated. Kriging was used to calculate the spatial distribution of the data and parameter.

\section{RESULTS AND DISCUSION}

At the end of the evaporation experiment, the degree of water repellency was measured using the WDPT test. Figure 3 shows the dependence of the WDPT on the water content. The water contents varied between 0.013 and $0.152 \mathrm{~m}^{3} \mathrm{~m}^{-3}$. Low WDPT occurred at high water contents. Soil was wettable or slightly water repellent for water contents above $0.14 \mathrm{~m}^{3} \mathrm{~m}^{-3}$. Water repellency occurs below $0.12 \mathrm{~m}^{3} \mathrm{~m}^{-3}$, turning strongly water repellent between 0.10 and $0.03 \mathrm{~m}^{3} \mathrm{~m}^{-3}$. At the dry end of the scale, the degree of water repellency decreased again. The measurements correspond very well with the field sampling of Täumer et al. (2005), who observed a critical water content of $0.12 \mathrm{~m}^{3} \mathrm{~m}^{-3}$ for this site, depending slightly on the amount of organic matter.

The conditions at the beginning of the experiments were similar to the conditions in the field. An equilibrium process inside the soil cores could, however, occur between the sampling and the beginning of the evaporation experiment in the laboratory. Figure 4 shows the initial water content and matric potential distribution in a transect of $150 \mathrm{~cm}$ length and $10 \mathrm{~cm}$ depth. The average water content was $0.119 \mathrm{~m}^{3} \mathrm{~m}^{-3}$, with a minimum of $0.081 \mathrm{~m}^{3} \mathrm{~m}^{-3}$ and a maximum of $0.191 \mathrm{~m}^{3} \mathrm{~m}^{-3}$. The values show a drier region at the position of $80 \mathrm{~cm}$, a wetter region at $50 \mathrm{~cm}$. TDR measurements close to the sampling site showed similar water content distributions at the date of the sampling. The drier and wetter regions expanded over more than one core. The matric potential distribution showed different results. Most cores had similar values with an average between -85 and $-108 \mathrm{~cm}$. The drier region showed a lower matric potential $(-15$ at $70 \mathrm{~cm}$ and -377 at $80 \mathrm{~cm})$, and the position at $150 \mathrm{~cm}$ higher matric potentials $(-48 \mathrm{~cm})$. The measurements represented the different hysteretic conditions for the soil cores. The water contents in combination with the results of the WDPT measurements indicate that at least the drier parts at $80 \mathrm{~cm}$ were water repellent. The average bulk density of the 15 cores was $1.30 \mathrm{~g} \mathrm{~cm}^{-3}$, with a minimum of $1.25 \mathrm{~g} \mathrm{~cm}^{-3}$ and a maximum of $1.39 \mathrm{~g} \mathrm{~cm}^{-3}$. The average porosity was $0.500 \mathrm{~m}^{3} \mathrm{~m}^{-3}$, and the amount of organic matter (measured for two cores) was $4.3 \%$.

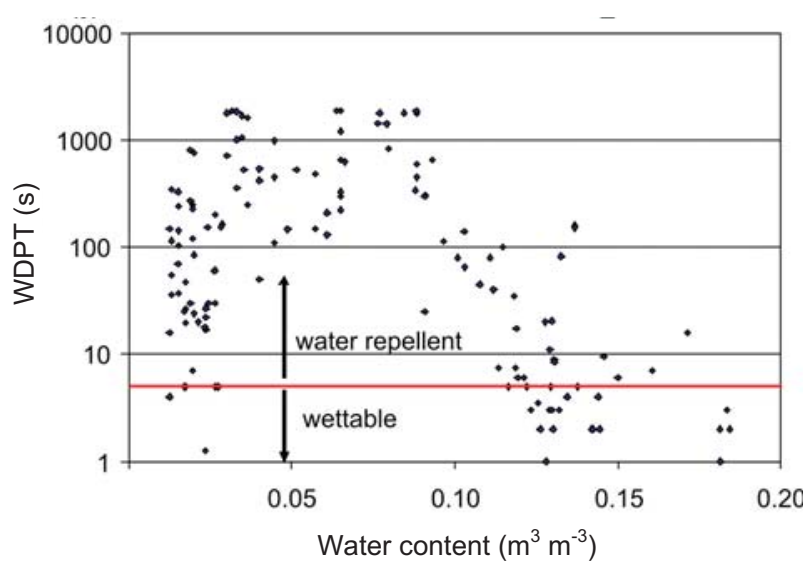

Fig. 3. Water drop penetration times (WDPT) as a function of the volumetric water content.

a

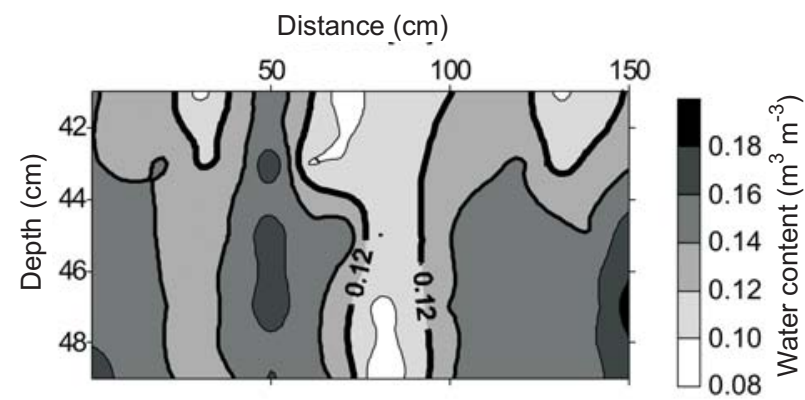

b

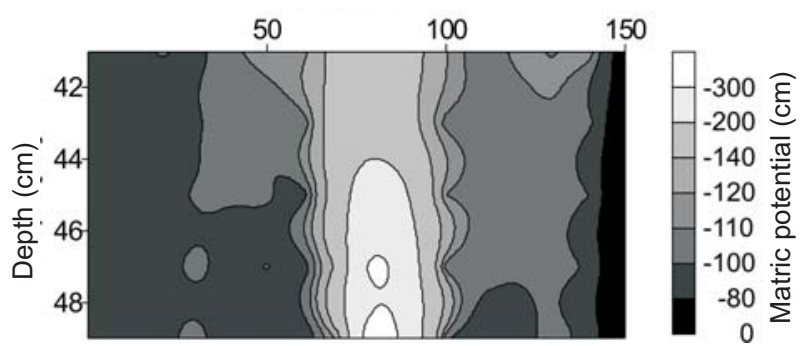

Fig. 4. Water content (a) and the matric potential (b) at the beginning of the evaporation experiment. At a distance of $80 \mathrm{~cm}$, a dryer range appears that is considered water repellent.

The water retention curve was measured for five compartments in each core. The results of the highest compartment of the cores were not included in further calculations due to the high dynamics of the matric potential and water content changes just $1 \mathrm{~cm}$ below the evaporation surface. The measured water retention curves ( 57 for all cores at depths of 3, 5, 7, and $9 \mathrm{~cm}$ ) are displayed in Fig. 5a. The different starting points of the retention curve show the wide range of 

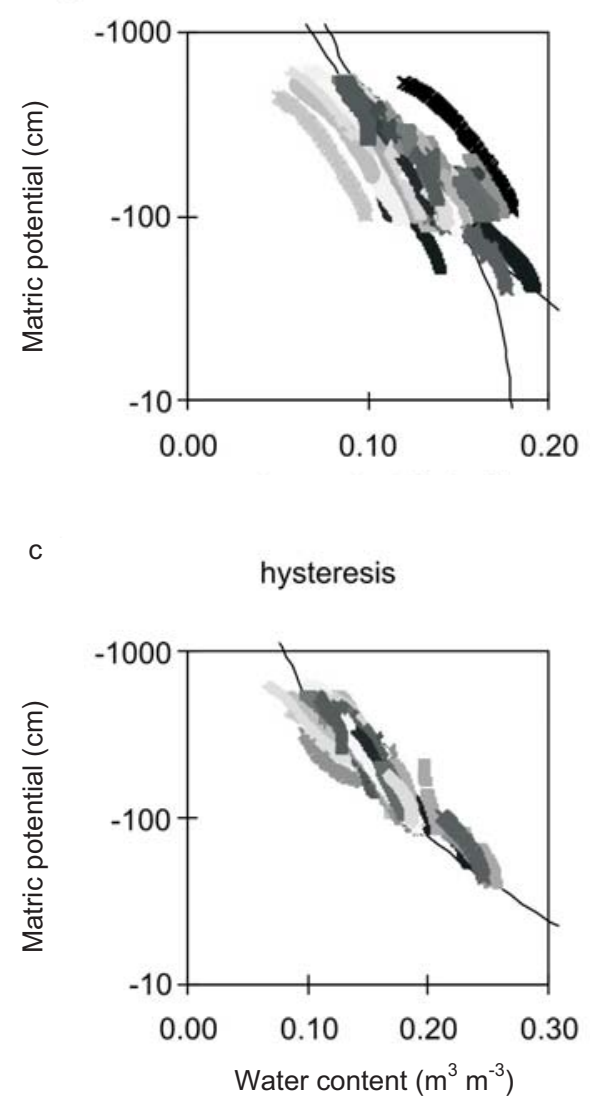
h-scaling

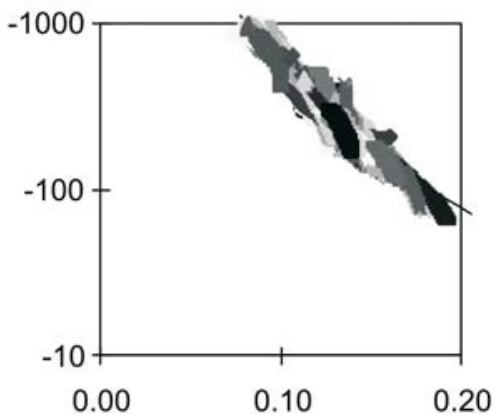
hysteresis and h-scaling

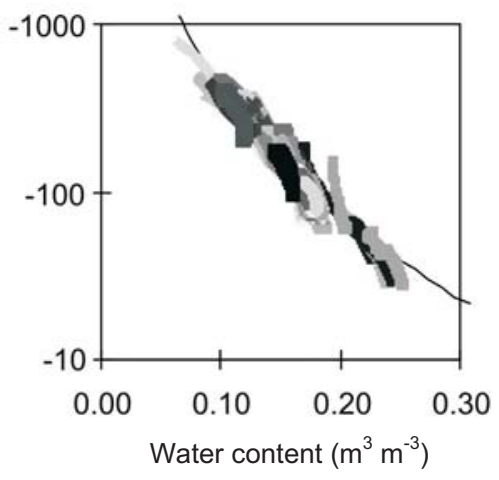

Fig. 5. Heterogeneity of the water retention: a - measured curves, b - scaled curves, $\mathrm{c}$ - with consideration of hysteresis, and $\mathrm{d}-$ combination of hysteresis and scaling.

water contents at the beginning of the experiment. Figure 5a presents two different van Genuchten functions, leading to similar deviations. The parameters $\left(\theta_{S_{3}}=0.182 \mathrm{~m}^{3} \mathrm{~m}^{-3}\right.$, $\left.\alpha=0.01 \mathrm{~cm}^{-1}, n=1.40\right)$ and $\left(\theta_{S}=0.500 \mathrm{~m}^{3} \mathrm{~m}^{-3}, \alpha=0.6 \mathrm{~cm}^{-1}\right.$, $n=1.32$ ) make it clear that there is not necessarily a unique solution for the van Genuchten parameter. Especially $\alpha$ is correlated with $\theta_{S}$. The average deviations of the estimated functions from the data were in the range of $0.01 \mathrm{~m}^{3} \mathrm{~m}^{-3}$, and the maximal deviation for a single retention curve was higher than $0.04 \mathrm{~m}^{3} \mathrm{~m}^{-3}$.

Two different approaches were used to describe the heterogeneity of the water retention curves:

- The scaling factors of the water retention curve were calculated using the matric potential measurements.

- The initial conditions of the water content and matric potential were used for the calculation of the hysteretic conditions according to Eq. (12), and the resulting data were subsequently scaled by the matric potential in the same way as in 1 .

It was necessary to use a fixed water retention function for the procedure of scaling. The saturated water content $\theta s$ was set equal to the average porosity of the cores of $0.500 \mathrm{~m}^{3}$ $\mathrm{m}^{-3}$, and the residual water content $\theta_{R}$ was set equal to the
Ta b l e 1. Mualem-van Genuchten parameter of the average water retention and unsaturated hydraulic conductivity

\begin{tabular}{lccccc}
\hline \multirow{2}{*}{ Parameter } & $\theta_{R}$ & $\theta_{S}$ & $\alpha$ & $n$ & $K_{S A T}$ \\
\cline { 2 - 6 } & $\left(\mathrm{m}^{3} \mathrm{~m}^{-3}\right)$ & $\left(\mathrm{cm}^{-1}\right)$ & & $\left(\mathrm{cm} \mathrm{d}^{-1}\right)$ \\
\hline $\begin{array}{l}\text { Water retention } \\
\text { stationary }\end{array}$ & 0.013 & 0.547 & 0.13 & 1.41 & - \\
$\begin{array}{l}\text { experiment }) \\
\begin{array}{l}\text { Unsaturated } \\
\text { hydraulic } \\
\text { conductivity }\end{array}\end{array}$ & - & - & 0.056 & 1.32 & 60.6 \\
\hline
\end{tabular}

lowest measured value of $0.013 \mathrm{~m}^{3} \mathrm{~m}^{-3}$. Independent stationary experiments were used to calculate the parameters $n$ and $\alpha$ of the main drainage curve $\left(n=1.41\right.$ and $\left.\alpha=0.13 \mathrm{~cm}^{-1}\right)$. Table 1 displays the van Genuchten parameters of the water retention and the unsaturated hydraulic conductivity. Due to this calculation procedure, the reference curve of the scaling is the main drainage curve of the soil.

Figure $5 \mathrm{~b}$ shows the results of the scaling. The average deviation for the retention curves is lower than $0.006 \mathrm{~m}^{3} \mathrm{~m}^{-3}$, and the maximum deviation is reduced from 0.04 to $0.012 \mathrm{~m}^{3}$ $\mathrm{m}^{-3}$. The scaling factors range from 0.68 to 5.1 with an average of 1.78 and a standard deviation of 0.65 . The average of 
the scaling factors is unequal to 1 , because the data was scaled using the main drainage curve which lies above the measured data.

Figure $5 \mathrm{c}$ includes the initial water content and matric potential for the water retention curve. The data were stretched along the water content axis until the initial values were located on the main drainage curve (according to Eq. (12)). Additionally, Fig. 5d includes a scaling along the matric potential axis. Due to the shifting, the deviation is in the same range as for the results without hysteresis. The average deviation is in the range of $0.0066 \mathrm{~m}^{3} \mathrm{~m}^{-3}$, and the maximal deviation is $0.013 \mathrm{~m}^{3} \mathrm{~m}^{-3}$. The scaling factors $\mathrm{h}$ reach from 0.63 to 1.37 with an average of 0.83 and a standard deviation of 0.12 .

Figure 6 displays the measurements of the unsaturated hydraulic conductivity as a function of the matric potential. In contrast to the water retention curve, the shape of the curve is similar for all measurements, and the differences between the cores and compartments are small. For the fitting of the data, the measured value of $K_{S A T}$ was used. $\mathrm{n}$ is similar to the value of the water retention curve (Table 1).

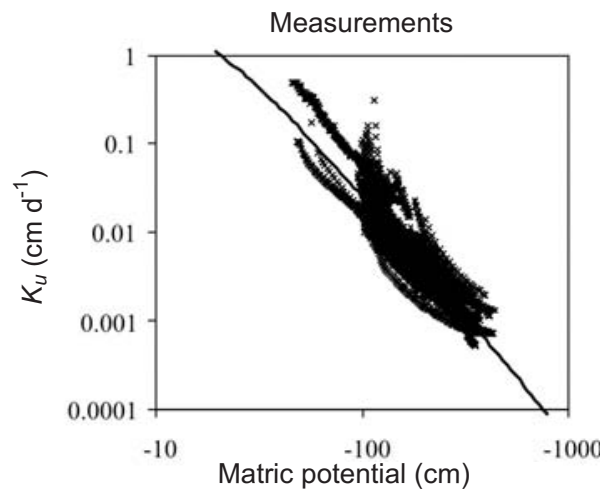

Fig. 6. The unsaturated conductivity of compartments in soil cores.

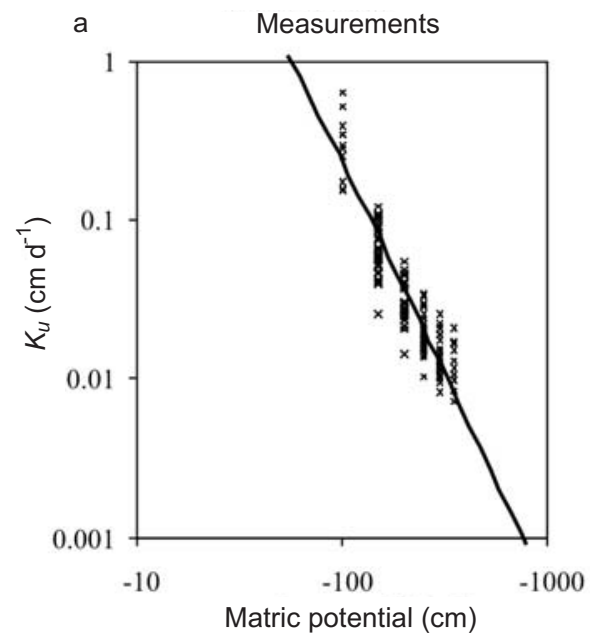

The parameter correlates strongly with the parameter $K_{S A T}$. In the driest core (at position $80 \mathrm{~cm}$ ), the unsaturated hydraulic conductivity could not be measured. The matric potentials at the beginning were too low, so that the values quickly exceeded the measurement range of the tensiometers. Figure 7 shows the scaling of the unsaturated hydraulic conductivity. The conductivities at matric potentials of -100 , $-150,-200,-250,-300$ and $-350 \mathrm{~cm}$ were calculated. The average difference between the measured values and the fitted hydraulic functions reach a factor of 1.7 $(\overline{\Delta \log (K)}=0.13)$. Using a scaling factor for the matric potential, all measurements come closer to the fitted curve. The average deviation is reduced to a factor of 1.3 $(\overline{\Delta \log (K)}=0.22)$. The scaling factors range from 0.73 and 1.33 with an average of 1.00 and a standard deviation of 0.12 .

The measured scaling factors for the water retention (with and without hysteresis) were more likely to be distributed normally than log normally. The p-values for the Kolmogorov-Smirnov-Test were 0.01 and 0.075 for the normal distribution and 0.19 and 0.27 for the lognormal distribution. For the hydraulic conductivity, the scaling factors were neither normally nor log normally distributed. The results show a more equal distribution.

Hendrayanto et al. (2001) measured a much larger standard deviation for the scaling factor, but they scaled the hydraulic function for the whole profiles and not for a single horizon. They presented data for the variance of $\ln \left(\alpha_{S}\right)$ of other studies which had measured scaling factors for the water retention. The values range between 0.06 and 1 for the variance of curve scaling for nine different sites, with smaller sites $\left(<100 \mathrm{~m}^{2}\right)$ showing values below 0.11 . This is comparable to our results with values of 0.09. Deurer et al. (2000) and Mallant et al. (1996) came to similar results for the water retention as well. Tuli et al. (2001) measured slightly higher variances of the scaling factors.

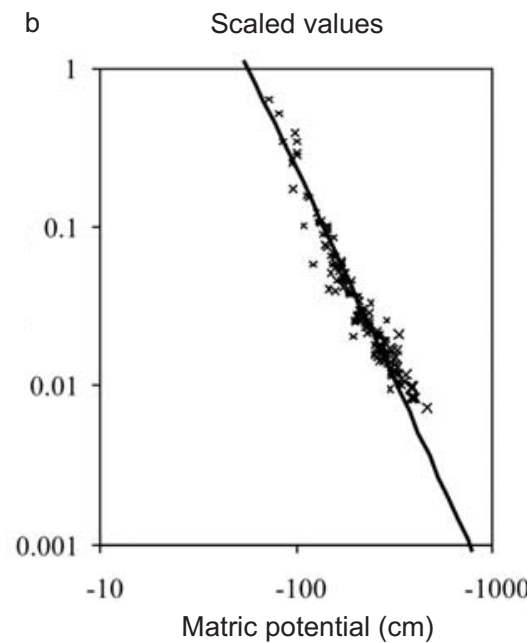

Fig. 7. The effect of scaling of the unsaturated hydraulic conductivity. The measured values at defined matric potentials $(100$ to $350 \mathrm{~cm})$ (a) and scaled values (b). 


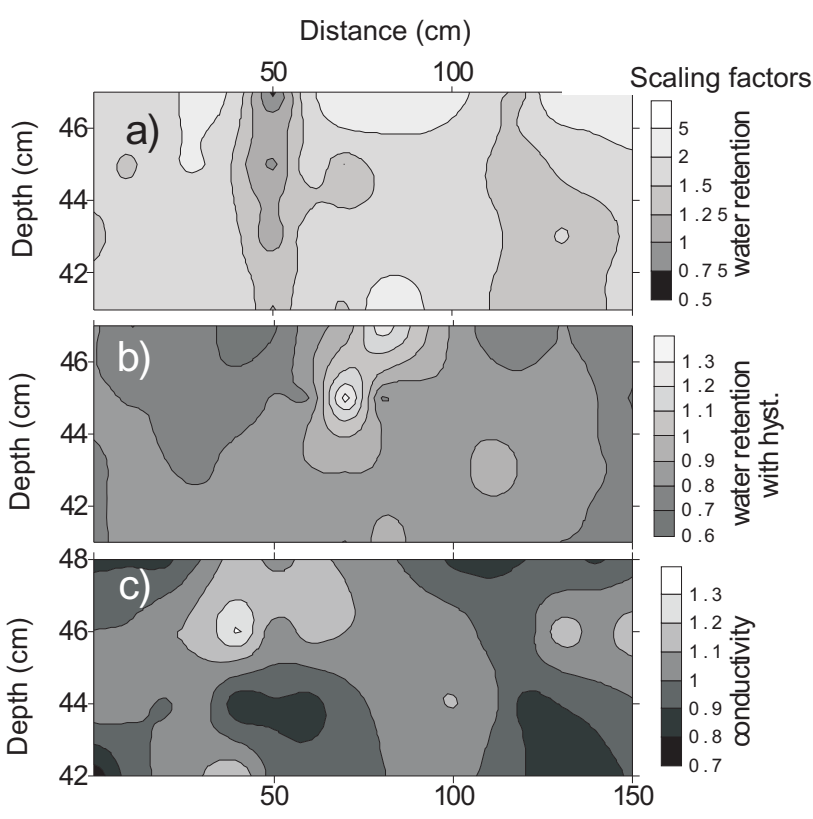

Fig. 8. The spatial distribution of the scaling factors for the water retention curve: $\mathrm{a}$ - without hysteresis, $\mathrm{b}$ - with hysteresis, and $\mathrm{c}$ - unsaturated hydraulic conductivity.

The measured heterogeneity for the unsaturated hydraulic conductivity was smaller than the values measured by Tuli et al. (2001) and much smaller than the values for the saturated conductivity measured by Mallants et al. (1996). Kelleners et al. (1999) measured scaling factors with standard deviations about three times larger than those in our experiment.

Figure 8 shows the spatial distribution of the scaling factor. In the lowest compartment of the cores, the matric potential gradients were often close to equilibrium, so that the calculation of the unsaturated hydraulic conductivity was not possible.

Figure 9 displays the connection between the scaling factors of the unsaturated conductivity and the scaling factors of water retention curves. The values of the scaling-factors for the water retention were calculated at the positions of the conductivity measurements (Fig. 8). There is no correlation if the hysteretic approach of Kool and Parker (1987) is taken into account and only a slight correlation $\left(\mathrm{R}^{2}=0.30\right)$ if not. This proves the independence of the heterogeneity of the water retention and the hydraulic conductivity.

Semivariograms of the initial water content, the initial matric potential and the unsaturated hydraulic conductivity (at matric potentials of 150,200, 250 and $300 \mathrm{~cm}$ ) are shown in Fig. 10. The semivariogram for the initial water content

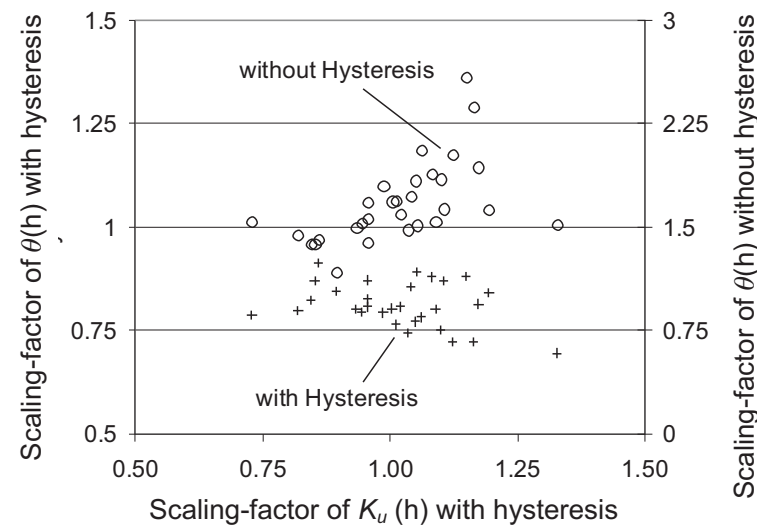

Fig. 9. Scaling factor of the water retention curve (with and without consideration of hysteresis) in dependence on the scaling factor of the hydraulic conductivity.
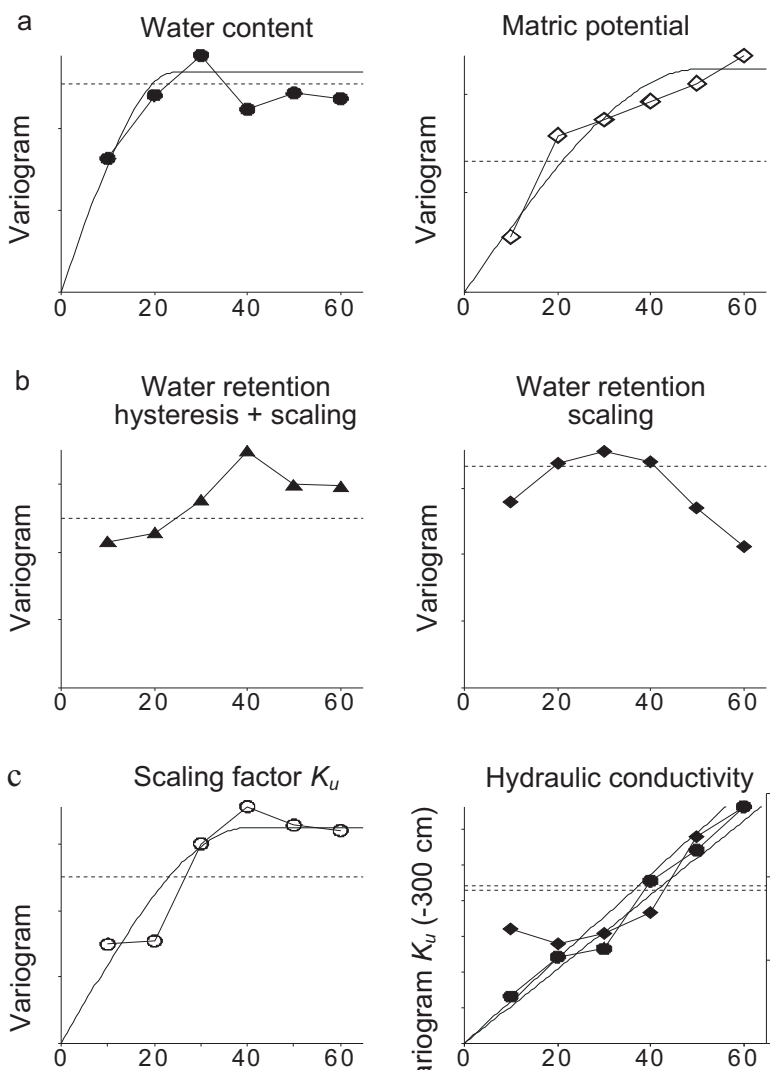

Lag distance $(\mathrm{cm})$

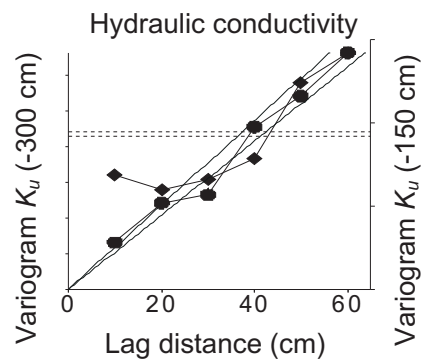

Fig. 10. The semivariograms of: a -initial water content and matric potential, $\mathrm{b}$ - scaling factors of water retention, and $\mathrm{c}$ - unsaturated hydraulic conductivities and scaling factor of the conductivity. The dotted lines are the variances, the solid one is a spherical model. The model was fitted to those data, where reasonable results could be achieved. 
shows a clear correlation length. It reaches a maximum at $30 \mathrm{~cm}$, decreases slightly, and stays on a plateau. Using a spherical function to fit the data, a correlation length of $24 \mathrm{~cm}$ was determined. The value corresponds with the typical dimensions of water repellent or wettable spots. The data of the unsaturated hydraulic conductivity leads to different results. No correlation length can be found, a trend can be seen along the transect. Due to the length of the transect of $150 \mathrm{~cm}$, the correlation length could not be determined.

\section{CONCLUSIONS}

1. The results show differences in the spatial distribution of the water retention and the unsaturated hydraulic conductivity. Altogether, it is surprising that the unsaturated hydraulic conductivity depends only slightly on the initial conditions of the water contents in the field.

2 . The heterogeneity of the soil water content and water retention curves was higher than the heterogeneity of the unsaturated hydraulic conductivity.

3. Scaling-factors can describe the heterogeneity of the hydraulic functions.

4. The scaling factors of both functions were independent from each other.

5. The unsaturated hydraulic conductivity as a function of the matric potential was independent of the initial hysteretic status of the soil.

6. These conclusions have to be considered for the numerical simulation of the water flow. Therefore, the concept of scaling of the hydraulic functions can be used to describe the heterogeneity of the hydraulic functions. However, it is necessary to use different scaling factors for the hydraulic conductivity and the water retention. The results indicate that the hydraulic conductivity should be described as a function of the matric potential, and should be independent of hysteresis of the water retention.

\section{ACKNOWLEDGEMENT}

This contribution is dedicated to our colleague and friend Ryszard Walczak. Whenever and wherever we metwe always had a wonderful time and fruitful discussions about soil physics, philosophy and life. We are very thankful for this brainstorming time of ideas - we still miss him. We would like to thank the Deutsche Forschungsgesellschaft (DFG) for their financial support.

\section{REFERENCES}

Basile A., Ciollaro G., and Coppolla A., 2003. Hysteresis in soil water characteristics as a key to interpreting comparisons of laboratory and field measured hydraulic properties. Water Resour. Res., 39(2), 1355-1367.

Carminati A., Kaestner A., Lehman P., and Flühler H., 2008. Unsaturated water flow across soil aggregate contacts. Adv. Water Res., 31, 1221-1232.
Clausnitzer V., Hopmans J.W., and Nielsen D.R., 1992. Simultaneous scaling of soil water retention and hydraulic conductivity curves. Wat. Res. Res., 28, 19-31.

Deurer M., Duijnisveld W.H.M., and Böttcher J., 2000. Spatial analysis of water characteristic functions in a sandy podzol under pine forest. Wat. Res. Res., 36, 2925-2935.

Hendrayanto D., Kosugi K., and Mizuyama T., 2001. Scaling hydraulic properties of forest soils. Hydrol. Proces., 14, 521-538.

Kelleners T.J., Beekma J., and Chaudhry M.R., 1999. Spatially variable soil hydraulic properties for simulation of fieldscale solute transport in the unsaturated zone. Geoderma, 92, 199-215.

Kodesova R., Kutilek M., Vesela J., and Matula S., 2003. Scaling of two-phase pressure-saturation releationships: water-air and oil-air systems. Int. Agrophysics, 17, 157-162.

Kool J. B. and Parker J.C., 1987. Development and evaluation of closed-form expressions for hysteretic soil hydraulic properties. Water Res. Res., 23, 105-114.

Kosugi K. and Hopmans J.W., 1998. Scaling water retention curves for soils with lognormal pore-size distribution. Soil Sci. Soc. Am. J., 62, 1496-1505.

Letey J., Carrillo M.L.K., and Pang X.P., 2000. Approaches to characterize the degree of water repellency. J. Hydrol., 231-232, 61-65.

Lipiec J., Walczak R., Witkowska-Walczak B., Nosalewicz A., Słowińska-Jurkiewicz A., and Sławiński C., 2007. The effect of aggregate size and pore structure of silt loam soils of different genesis. Soil Till. Res., 97, 239-246.

Luckner L., van Genuchten M.T., and Nielsen D.R., 1989. A consistent set of parametric models for the two-phase flow of immiscible fluids in the subsurface. Water Res. Res., 25, 2187-2193.

Mallants D., Mohanty B.P., Jacques D., and Feyen J., 1996. Spatial variability of hydraulic properties in a multi-layered soil profile. Soil Sci., 161, 167-181.

Millan H. and Gonzalez-Posada M., 2005. Modeling soil water retention scaling. Comparison of a classical fractal model with a piecewise approach. Geoderma, 125, 25-38.

Miller E. E. and Miller R.D., 1956. Physical theory for capillary flow phenomena. J. Appl. Phys., 27, 324-332.

Mualem Y., 1976. A new model for predicting the hydraulic conductivity of unsaturated porous media. Water Res. Res., 12(3), 513-522.

Mualem Y., 1984. A modified dependent domain theory of Hysteresis. Soil Sci., 137, 283-291.

Naasz R., Michel J.-C., and Charpentier S., 2005. Measuring Hysteretic Hydraulic Properties of Peat and Pine Bark using a Transient Method. Soil Sci. Soc. Am. J., 69, 13-22.

Plagge R., 1991. Bestimmung der ungesättigten hydraulischen Leitfähigkeit. Ph.D. Thesis, Technical University, Berlin, Germany.

Rockhold M.L., Rossi R.E., and Hills R.G., 1996. Application of similar media scaling and conditional simulation for modeling water flow and tritium transport at the Las Cruces trench site. Water Res. Res., 32, 595-609.

Roth C.H., Malicki M.A., and Plagge R., 1992. Empirical evaluation of the relationship between soil dielectric constant and volumetric water content as the basis for calibrating soil moisture measurements by TDR. Soil Sci., 43, 1-13. 
Russo D. and Bresler E., 1980. Scaling soil hydraulic properties of a heterogeneous soil. Soil Sci. Soc. Am. J., 44, 681-683.

Schlenther L., Marschner B., Hoffmann C., and Renger M., 1996. Ursachen mangelnder Anwuchserfolge bei der Aufforstung der Rieselfelder in Berlin-Buch - bodenkundliche Aspekte. Verh. Ges. Ökol., 25, 349-359.

Sławiński C., Witkowska-Walczak B., Lipiec J., and Nosalewicz A., 2011. Effect of aggregate size on water movement in soils. International Agrophys., 25, 53-58.

Sposito G., 1998. Scale dependence and scale invariance in hydrology. Cambridge University Press, Cambridge, UK.

Stoffregen H., 1998. Hydraulische Eigenschaften deponiespezifischer Materialien unter Berücksichtigung von Temperaturänderungen. Ph.D. Thesis, Technical University, Berlin, Germany.

Täumer K., Stoffregen H., and Wessolek G., 2005. Determination of repellency distribution using soil organic matter and water content. Geoderma, 125, 107-115.
Tuli A., Kosugi K., and Hopmans J.W., 2001. Simultaneous scaling of soil water retention and unsaturated hydraulic conductivity functions assuming lognormal pore-size distribution. Advances Water Res., 24, 677-688.

van Genuchten M.T., 1980. A closed-form equation for predicting the hydraulic conductivity of unsaturated soils. Soil Sci. Soc. Am. J., 44, 892-898.

Warrick A.W., Mullen G.J., and Nielsen D.R., 1977. Scaling field measured soil hydraulic properties using a similar media concept. Water Resour. Res., 13, 355-362.

Witkowska-Walczak B., 2006. Hysteresis between wetting and drying processes as affected by soil aggregate size. Int. Agrophysics, 20, 359-365.

Zhu J. and Mohanty B.P., 2006. Effective factor for transient infiltration in heterogeneous soils. J. Hydrol., 39(1-4), 96-108. 